\title{
EL ESPACIO GEOGRÁFICO-HISTÓRICO DEL CAMPO DE MONTIEL
}

Desde esta joya del Renacimiento, cargada de historia y de leyenda que es Villanueva de los Infantes, centro geográfico, político, eclesiástico y administrativo del Campo de Montiel, comparezco ante ustedes en esta luminosa mañana, bajo los cielos eternos de esta geografía aludida por D. Miguel de Cervantes, para hablarles del «Espacio Geográfico e Histórico del Campo de Montiel».

Seguramente que en términos parecidos, pero más evocadores, en estos días se dirá que Cervantes, colocado en el cruce de dos épocas: Renacimiento y Barroco, escribió el libro que más gloria ha dado a España y fama a La Mancha, una obra de tanta vitalidad en la literatura que sigue respirando arte y admiración en todos.

Pero nosotros vamos a comenzar señalando que en los años en que viene al mundo Cervantes, el Campo de Montiel era prácticamente una comunidad de villazgos, puesto que los pocos lugares que aún no se habían convertido en villa (Carrizosa, Cañamares y Santa Cruz de los Cáñamos) lo serían después. En tanto, España se hallaba en un momento de inflexión, puesto que del esplendor de la primera parte del XVI se pasa a una fase de decadencia al final del mismo, haciéndose penosa y trágica en los albores del XVII, justo cuando Miguel de Cervantes traspasa con su muerte los umbrales hacia una vida llena de gloria.

Para que sepamos más certeramente la pertenencia jurídico-administrativa a la que el Campo de Montiel estaba adscrita en aquellos momentos en que Cervantes lo atravesaba en sus viajes como recaudador de impuestos, diremos que en 1591, la Corona de Castilla ${ }^{1}$

1 Archivo General de Simancas, leg. 1301. Contadurías Generales. 
aparece dividida en provincias, aunque no existiera ninguna división administrativa con ese nombre. Una de ellas fue la muy extensa provincia de Toledo que se componía de siete partidos: Toledo, Ciudad Real, Mesa Arzobispal de Toledo, Campo de Calatrava, Partido de Ocaña, Partido del Campo de Montiel y Partido de Alcaraz.

Ya el siglo XVII muestra una profunda crisis política y económica en España, pudiéndose decir que no se dio ninguna división administrativa de importancia en el conjunto del territorio. Sin embargo, ocurrió que en 1691, considerando el gobierno que la provincia de Toledo tenía demasiada extensión, la dividió en dos, ya que así interesaba para la ejecución del sistema de Hacienda entonces concebido, formando con los partidos de Alcaraz, Almagro (Campo de Calatrava), Ciudad Real e Infantes (Campo de Montiel) la provincia de La Mancha, cuya capital fue Ciudad Real. Algún tiempo después se le agregaron los pueblos de la Orden de Santiago que constituían la Mesa de Quintanar de la Orden, y por Real Orden de 8 de diciembre de 1799, los del Gran Priorato de San Juan.

Por otro lado, podemos señalar que Cervantes, buen conocedor de tantos aspectos geográficos y administrativos concibió una idea magistral cuando queriendo reseñar su conocimiento del Campo de Montiel y aludiendo a Don Quijote dijo: "comenzó a caminar por el antiguo y conocido Campo de Montiel. Y era la verdad que por él caminaba» ${ }^{2}$, o cuando en otro momento, ya en el capítulo VII (Parte I) nos dice "Acertó Don Quijote a tomar la misma derrota y camino que él había tomado en su primer viaje, que fue por el Campo de Montiel, por el cual caminaba con menos pesadumbre que la vez pasada, porque por ser la hora de la mañana y herirles a soslayo los rayos del sol, no les fatigaban» ${ }^{3}$.

$\mathrm{Al}$ referirnos a las tierras que Don Quijote y Sancho conocieron a su paso por los campos montieleños, podemos decir que estaban surcadas de caminos polvorientos que separaban sembrados y baldíos, viñedos y olivares y, que en su largo caminar, de vez en cuando tropezaban con cuadrillas de arrieros, con lentos campesinos tirando del rucio o con alguna moza escondiendo bajo el pañuelo y el sombrero la belleza y el rubor. También aseguramos que a su paso al pie de los cerros de Alcubillas, Fuenllana, Alhambra y Montiel verían sus castillos maltrechos y agotados por la dura lucha prestada a la Reconquista.

Abundando más en este aspecto, y fijándonos en la hidrografía, diferimos de Blazquez ${ }^{4}$ cuando alude al hecho de que Cervantes no

\footnotetext{
2 Parte Primera, Capítulo II.

3 Parte Primera, Capítulo VII.

4 Blázquez y Delgado Aguilera, ANTonio, La Mancha en tiempo de Cervantes. Ciudad Real, 1898, p. 23.
} 
cita a los ríos Azuer y Jabalón, que son los que atraviesan este Campo, debido en su opinión a que "no merecen otra cosa ya que son ríos malsanos que siembran la peste y alejan de sus orillas los pueblos, ríos sin agua, sin industria, sin el verde de las huertas y sin la sombra de sus árboles»; pues creemos que eran muchas las huertas y alamedas que hermoseaban las riberas de ambos ríos.

Sin querer extendernos más en cuanto a los aspectos geográficos, tampoco coincidimos con Blázquez cuando al hablar del ámbito del Campo de Montiel en la época de Cervantes define así sus limites: "...comprendía desde el Ayozo bastante al S. de Argamasilla de Alba, y desde cerca de Manzanares y Membrilla hasta Beas, Santisteban y Montizón en la provincia de Jaén, llegando por Levante a abarcar casi todas las Lagunas de Ruidera, el pueblo de la Osa de Montiel, la ermita de San Pedro, la Cueva de Montesinos y el castillo de Rochafrida» ${ }^{5}$.

El desacuerdo lo mostramos respecto a la zona sur, puesto que las últimas poblaciones que figuran en el Censo de la Corona de Castilla de 1591 en esta zona del Campo de Montiel son: Castellar de Santiago y Villamanrique. Beas y Santisteban quedan en los límites de la ciudad de Jaén y su provincia.

En cuanto a los caminos que pudieron utilizar Don Quijote y su escudero, bien sabía Cervantes, como geógrafo excepcional que fue, que los más importantes de los que cruzaban el Campo de Montiel eran los que desde Madrid iban a Andalucía. Tengamos presente que en 1624, sólo unos pocos años después de publicarse la segunda parte del Quijote, y con motivo de visitar las costas andaluzas, Felipe IV ante el temor de un posible golpe de mano de los mercaderes ingleses (como después se vino a demostrar), optó por el que viniendo desde Villarta de San Juan (donde comieron el día 12 de febrero), continuaba por La Membrilla, Alcubillas, Cózar y La Torre de Juan $\mathrm{Abad}^{6}$. Este camino real lo debía conocer muy bien Cervantes, pues como ya hemos apuntado, al ser recaudador de impuestos de algunas poblaciones de Andalucía debió atravesarlo en diferentes ocasiones.

Profundizando más en la caminería, recordamos a Delgado Merchán ${ }^{7}$ cuando al referirse a La Mancha decía: «...han desaparecido como por encanto las sendas, encrucijadas y vericuetos recorridos en busca de aventuras sin ventura por el Ingenioso Hidalgo", y es que por estos descampados caminos del Campo de Montiel hace ya muchos años que se acabó de soñar que por cualquier esquina

5 Ibidem, p. 10.

6 Fernández Guerra y Orbe, Aureliano, Obras de F. de Quevedo, t. I.

7 Delgado Merchán, Luis, Historia documentada de Ciudad Real (La Judería, la Inquisición y la Santa Hermandad), 2. ${ }^{\mathrm{a}}$ ed. Ciudad Real, 1907, p. 25. 
aparecería un Camacho el rico o un Basilio el pobre, un Sansón Carrasco, un Caballero del Verde Gabán, cuadrilleros de la Santa Hermandad (o ladrones en cuadrilla como los llamó Alonso Quijano), y Aldonzas y Maritornes al estilo de la época. También han dejado de darse en este Campo de Montiel actitudes quijotescas y pancescas, sin dejar de reconocer por eso que el alma de aquella leyenda vive aún, a pesar de las transformaciones que traen los siglos, en no pocos descendientes de la inmortal pareja.

Históricamente, el Campo de Montiel de la segunda mitad del siglo XVI reedificaba en sus pueblos las pequeñas iglesias transformándolas en otras más grandiosas, a la vez que se poblaba, aún más, de ermitas y santuarios. La Orden de Santiago, que tanto colaboró en repoblar su territorio, poseía grandes fincas, dedicándose la mayor parte de ellas a la ganadería; si bien sus ingresos más importantes derivaban del cobro del diezmo. Además, sus villas formaban entidades para beneficiarse de los aprovechamientos comunales de pastos y leña, en tanto que no cejaba en su lucha con el Honrado Concejo de La Mesta, que como bien sabemos ejerció un fuerte poder sobre la trashumancia, aunque por entonces ya había iniciado su declive.

En cuanto a su demografía, Cervantes conoció el incremento de vecinos que se produjo en el Campo de Montiel a partir de 1571, cuando ya se había pacificado la sublevación de Las Alpujarras, pues, como consecuencia de la llegada de moriscos, poblaciones como Albaladejo, Alcubillas, Villamanrique, y, sobre todo, Torrenueva, Membrilla y Villanueva de los Infantes experimentaron un ascenso más que notable en su población. Después, la sangría demográfica de 1580, apreciada en el Censo de 1591, tiene clara incidencia en el Campo, pues Almedina, Cózar, Membrilla, Torrenueva y especialmente Montiel sufren un acusado descenso. No obstante, hay excepciones como Terrinches y La Puebla que aumentan ligeramente su población, y Villanueva de los Infantes, que continua su progresivo aumento. En esto posiblemente tuvo que ver el cambio de Vicaría a éste último en detrimento de Montiel.

La expulsión de los moriscos en 1609, aunque el Decreto que nos afectó fue del año 1610, no hace sino que continuar una pendiente muy pronunciada que llega hasta 1620 , pudiéndose decir que Cervantes supo en sus postreros años que fueron muchos los que también abandonaron su antiguo y conocido Campo de Montiel. Infantes, Membrilla y La Solana, por este orden, estaban a la cabeza del número de vecinos; por el contrario Alcubillas, La Puebla y La Osa eran los menos poblados, sin incluir la reciente villa de Carrizosa y los lugares de Cañamares, Santa Cruz de los Cáñamos y Torres que eran aldeas. 
De suma importancia resulta el tema de los hidalgos, la clase más baja de la nobleza y que por aquella época se veían inmersos en una decadencia de la que no volverían a recuperarse. Serían ya una entelequia, momias andantes y carentes de sentido con un elemento común que los mantiene unidos como era su ideología. Su tradicional desprecio al trabajo manual les condujo aún más a la ruina. Las mismas leyes contribuían a esa mísera condición, puesto que cualquier actividad manual les hacía perder la hidalguía. Únicamente a finales del siglo XVII se les permitió no trabajar, pero sí dirigir talleres sin renunciar a su condición social. De todas formas, muchos de ellos se dedicaban a la vida intelectual, lo que les hacía participar en la vida activa. Otros como Don Quijote a enredarse en aventuras quiméricas.

En casi todas las villas del Campo de Montiel había hidalgos y en algunas gran número en proporción a sus vecinos. Este es el caso de Alhambra, Almedina, Cózar, Torre de Juan Abad, Villahermosa y Villamanrique. En términos absolutos destacan por su elevado número Terrinches y Villanueva de los Infantes. En muchos pueblos los hidalgos ostentaban la mitad de los cargos públicos.

En estos años en que Cervantes escribió e ideó su famoso héroe, se trató de instaurar la unidad de la fe y de velar porque ésta, quedase pura de toda contaminación y desviación. Para España dicha política supuso un cambio radical; se pasa de una actitud de convivencia, de neutralidad, y hasta cierto punto de tolerancia hacia las confesiones no cristianas, a una actitud intransigente, rigurosa y de persecución ${ }^{8}$ que se llevó a cabo a través de la Inquisición.

En general los procesos inquisitoriales en el Campo de Montiel guardan una cierta proporción con el número de vecinos. Lógicamente donde más procesos se dieron fue en Villanueva de los Infantes. La Solana, a pesar de ser inferior en habitantes, tuvo más procesos que La Membrilla. A éstos le siguieron Torre de Juan Abad, Villahermosa, Montiel, Alhambra, Alcubillas, etc. Digamos finalmente que los procesos de los pueblos del Campo de Montiel tenían lugar en el Tribunal de Murcia.

Para saber el escenario y el clima mental en que vivieron nuestros antepasados coetáneos de Cervantes, hemos de fijarnos en como la avalancha de males que pareció abatirse sobre el siglo XVII tuvo sus consecuencias mágicas y místicas provocando un confuso ambiente de exaltación que hacía huir de la realidad a las gentes o las impelía a buscar seguridades trascendentes con las que responder

8 Historia de España, dirigida por MANUEL TUÑón DE LARA, t. V: La frustración de un imperio (1476-1714). Barcelona, Labor, 1987. 
a sus inquietudes cotidianas. Así la hechicería y la brujería, tan generalizadas en el ámbito rural, tuvieron bastante aceptación en esta época y en este Campo de Montiel. La noche brujeril por excelencia era la de San Juan, es decir, la más corta del año, donde las propiedades mágicas de las cosas alcanzaban su cenit.

Finalmente, y siguiendo a López Martínez ${ }^{9}$, podemos decir que el ser ésta la tierra elegida por Cervantes para crear su gran arquetipo universal, ya es motivo suficiente como para que nos sintamos muy satisfechos. Algo tendrá esta tierra cuando a ella llegaron las devociones de Cervantes, y las del fabuloso don Francisco de Quevedo, del que tanto se sabe y tanto se habla en esta región.

No cabe duda de que el amor de Cervantes por la Mancha y por este Campo de Montiel fue grande, porque siempre que Don Quijote es derrotado lo es fuera de esta tierra. Cervantes no se hubiese atrevido a derrotar a Don Quijote aquí, tuvo que irse de ella para infringirle esa vergüenza que el Ingenioso Hidalgo llevó tan profundamente que hizo que muriera de melancolía.

Por lo expresado, podemos afirmar que si Cervantes se encontrara entre nosotros contemplando el brillo que produce el sol al fijar sus rayos sobre los mares infinitos de los paisajes del Campo de Montiel, creemos que sería feliz de recordar aquella primera salida de Don Quijote y su fiel escudero por estas tierras. Y nosotros agradecidos por su presencia quedaríamos aquí en Villanueva de los Infantes con el alma encendida y el espíritu inquieto recordando los albores del siglo XVII, cuando la hidalga figura de Don Quijote sobre Rocinante y la redonda silueta de Sancho sobre el tranquilo jumento caminaban por el histórico y eterno Campo de Montiel.

JUAN JimÉNEZ BALLESTA Asociación «Amigos del Campo de Montiel»

9 LÓPEZ MARTínEZ, JosÉ, Conferencia sobre «La Geografía del Quijote» dada en Villanueva de los Infantes el 27 de abril de 1985. 